
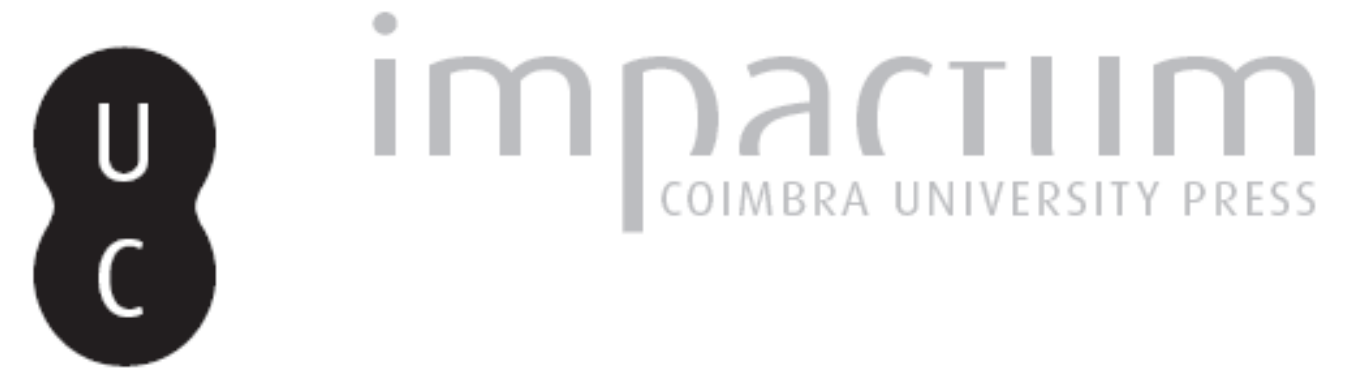

\title{
Vestígios antigos dos hidrossistemas romanos de Tomar
}

Autor(es): $\quad$ Ponte, Sálete da

Publicado por: Imprensa da Universidade de Coimbra

URL persistente:

URI:http://hdl.handle.net/10316.2/45447

DOI:

DOI:https://dx.doi.org/10.14195/1647-8657_35_8

Accessed : $\quad$ 26-Apr-2023 13:11:33

A navegação consulta e descarregamento dos títulos inseridos nas Bibliotecas Digitais UC Digitalis, UC Pombalina e UC Impactum, pressupõem a aceitação plena e sem reservas dos Termos e Condições de Uso destas Bibliotecas Digitais, disponíveis em https://digitalis.uc.pt/pt-pt/termos.

Conforme exposto nos referidos Termos e Condições de Uso, o descarregamento de títulos de acesso restrito requer uma licença válida de autorização devendo o utilizador aceder ao(s) documento(s) a partir de um endereço de IP da instituição detentora da supramencionada licença.

Ao utilizador é apenas permitido o descarregamento para uso pessoal, pelo que o emprego do(s) título(s) descarregado(s) para outro fim, designadamente comercial, carece de autorização do respetivo autor ou editor da obra.

Na medida em que todas as obras da UC Digitalis se encontram protegidas pelo Código do Direito de Autor e Direitos Conexos e demais legislação aplicável, toda a cópia, parcial ou total, deste documento, nos casos em que é legalmente admitida, deverá conter ou fazer-se acompanhar por este aviso. 
UNIVERSIDADE DE COIMBRA

FACULDADE DE LETRAS

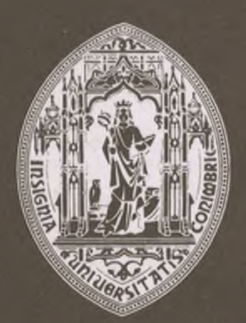

\section{CONIMBRIGA}

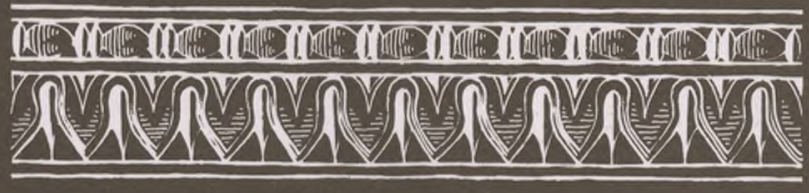

VOLUME XXXV - 1996 


\section{SÁlete DA Ponte}

Professora-coordenadora da Escola Superior de Tecnologia e Gestão de Tomar

\section{VESTÍGIOS ANTIGOS DOS HIDROSSISTEMAS ROMANOS DE TOMAR}

"Conimbriga" XXXV (1996) p. 189-205

RESUMO: Refere-se a descoberta, no território de Se Ilium (Tomar), de estruturas

romanas destinadas à captação, elevação e armazenamento de água: fontes, barragem, açudes, aqueduto e tanques. Dá-se particular ênfase ao estudo da barragem de Chocapalhas, situada na ribeira da Lousã (freguesia da Junceira); um muro rectilínio, de opus incertum, com blocos calcários unidos por argamassa de cal e areia; existe, a juzante, uma ponte romana e foram recolhidos, a cerca de $1 \mathrm{~km}$, entre Paixinha e Chocapalhas, materiais cerâmicos denunciadores da provável existência de um núcleo urbano secundário.

RÉSUMÉ: On mentionne la découverte, au territorium de Sellium (aujourd'hui, Tomar), de structures hydrauliques romaines, notamment le barrage de Chocapalhas, situé dans la rivière de Lousã (freguesia de Junceira), ayant dans les proximités un pont romain; des tessons céramiques ont été recueillis à $1 \mathrm{~km}$ à peu près (un site urbain sécondaire?). 
(Página deixada propositadamente em branco) 


\section{VESTÍGIOS ANTIGOS DOS HIDROSSISTEMAS DE TOMAR}

\section{Introdução}

A acção arqueológica desenvolvida nestes últimos 10 anos no territorium de Sellium (Tomar) tem fornecido um conjunto de informações sobre os vários hidrossistemas hidráulicos antigos, nomeadamente no que concerne aos testemunhos romanos da cidade-capital da civitas. Detectámos na região tomarense vários vestígios materiais, correspondentes a estruturas romanas e post-romanas, de captação, elevação, armazenamento, distribuição e evacuação de água em Tomar. Referimo-nos a fontes, a poços, a tanques e a condutas de captação e distribuição das águas; são dignos de realce vestígios de estruturas de alvenaria relativas à regularização, ao represamento e ao reaproveitamento da força hidráulica para elevação das águas. Ilustraremos os testemunhos materiais antigos e mais representativos de Tomar, com particular incidência para as estruturas romanas de Sellium.

\section{Geografia}

A região de Tomar insere-se num espaço geográfico mais amplo, limitado, a poente, por Ourém, a norte por Ferreira do Zêzere, a sudoeste por Torres Novas, a sul, pelo Entroncamento. Esta vasta região é recortada por uma rede hidrográfica extensa e diversificada, na qual se enquadram os cursos primários, secundários e sazonais da bacia do Tejo. $\mathrm{O}$ curso de água mais importante é o Nabão, afluente do Zêzere e subafluente do Tejo, que corre numa extensão de cerca de $60 \mathrm{Kms}$, na direcção norte-sul. 
O seu curso, nesta região, segue "um corredor geomorfológico natural, designado por "depressão periférica", que é constituído pelo conjunto de terras baixas situadas entre o Tejo e Mondego e encaixadas entre o maciço antigo, a leste, e o maciço calcário da Estremadura Central, a oeste" (Daveau, 1980). Hoje, este corredor de ligação entre o Nabão e o Tejo foi interrompido, por acção da natureza e do homem. A documentação antiga, medieval e moderna constitui importante fonte histórica sobre a navegabilidade do Nabão (0. A juzante do Nabão, a ponte e açude da Marianaia eram já conhecidos no tempo de D. Teresa(mãede D. Afonso Henriques), como porto de Marianaia, em 1334 (ATT, Tombo de Santa Maria do Olival - Cf. Anais de Tomar - 1137 a 1453 - Tomar, 1972, p. 237).

É evidente que a quantidade de dados paleogeográficos é ainda insuficiente para avaliar a capacidade total da rede hidrográfica desta região. Poder-se-á, contudo, afirmar que o clima temperado, a abundância de águas e a riqueza de bons solos agrícolas fizeram desta região uma importante plataforma de ligação entre as regiões altas e as planícies de aluvião, onde as vias fluviais foram a chave fisiográfica da bacia terciária do Tejo. Estas evidências paleogeográficas favoreceram $\mathrm{o}$ estabelecimento de povos pré-históricos, o desenvolvimento e engrandecimento desta região, desde os Romanos até ao seu repovoamento na época templária, e ao esplendor das empresas da navegação henriquina. As águas do rio Nabão são formadas, a sudoeste de Ansião, pelas ribeiras de Ateanha e de Etampes, que correm, respectivamente, de nordeste para sudoeste e de noroeste para sudeste; depois, desde a I ${ }^{a}$ nascente, perto de Ansião, engrossam com a $2^{\text {a }}$ nascente, próximo do penedo da Águia, designado por fonte do Agroal, avolumando-se com a de outras nascentes, ribeiros e regatos, que a ela afluem, passando por uma cadeia de pequenos planaltos calcários. Referimo-nos aos calcários carsificados existentes entre o Agroal e o Prado, aproveitados pelo homem primitivo para abrigo e repouso, para depois, em épocas posteriores, os habitantes das povoações vizinhas (Porto Velho, Chãos, Fungalvaz, Cedreira, Simão, Fonte Quente) aproveitarem o material

(') CF. Ponte (S. da), O estuário do Tejo na rota do comércio romano, "Anais da Real Sociedade Arqueológica Lusitana”, 2a série, II, 1988, pp. $49-57$ (p. 53). Estrabão (livro III, 3, 1, da Geografia) refere-se a barcos de rio que singravam ao longo dos afluentes entre o Tejo e Moron. O barco de pesca usado no rio Nabão era designado por "canoas do Aguadeiro" (FERREIRA, 1976, pp. 86-89). 
pétreo para a construção e para o fabrico de olaria local. O calcário da Pedreira, de S. Simão e o "mármore" de Vale de Ovos foram largamente aplicados na construção, como hoje. A pedra de cal de S. Simão foi usada para o fabrico de argamassa, bem como para a caiação. Ainda em relação ao rio Nabão, constata-se que o seu alargamento se dá entre a Fonte Quente e a planície a jusante, onde teve assento Tomar romana, com as suas margens transformadas em terrenos férteis, para depois, a cerca de $8 \mathrm{Kms}$ a sul da cidade, nas proximidades da Matrena, se esgueirar por canais e cavidades estreitas até se confundir com as águas do rio Zêzere, próximo de Constança. Digamos que o vale do Nabão é recortado por múltiplos cursos de água, destacando-se a ribeira de Ceras, o ribeiro de Peniche, a ribeira da Lousã com os seus afluentes, o ribeiro do Algás e o do Barril, na margem esquerda, e as ribeiras da Sabacheira e da Beselga, esta com o seu afluente o Cerzedo, Sarzedo ou "Carregueiros", na margem direita. Por outro lado, as águas do rio Nabão, mais exactamente as do Agroal, sempre foram consideradas medicamentosas. O territorium de Sellium apresenta, ainda hoje, marcas fisiográficas e indícios arqueo-históricos de nascentes, poços, valas, tanques, cisternas, açudes e barragens destinados à regularização, captação, distribuição e aproveitamento hidráulico das águas do rio. Ocupar-nos-emos, por agora, dos indícios arqueológicos e das fontes escritas que fornecem alguns dados sobre os hidrossistemas antigos, mormente do período romano.

\section{Fontes Arqueo-Históricas}

Os autores medievos e modernos $\left(^{2}\right)$ referem-se aos sistemas de engenharia hidráulica introduzida no tempo da Reconquista pela Ordem Templária, para depois ser ampiamente desenvolvida pela Ordem de Cristo, sendo, na altura, o seu Administrador ou Grão-Mestre, o Infante D.Henrique, entre 1420 e 1457. As referências escritas medievais

pp. 25 e segs; CF. FERREIRA (Fernando), Coisas Simples da Terra Tomarense. O rio, os açudes e as rodas, Santarém, 1976, pp. 21-26; CF. GuIMARÃES (V.), As águas do Agroal, "Congresso de Hidrologia, Climatologia e Geologia Médica” , Lisboa, 1932, pp. 3-4 e 6-9; CF. Rosa (A.), História de Tomar, I-II, 1965 e 1982; CF. ROSA (Alberto de Sousa), Anais do Municipio de Tomar (=AMT), Tomar, 1971. 
atestam, efectivamente, as pré-existências ainda visíveis, ao longo das margens do rio Nabão, nomeadamente no espaço urbano, que serviu de sede à Ordem do Templo e à Ordem de Cristo. Digamos que esta documentação arqueo-histórica favorece o estudo dos vários mecanismos hidráulicos medievais, sendo insuficiente, ou mesmo quase imperceptível, para os periodos históricos mais antigos. Pouco conhecemos sobre o aproveitamento e sistema de captação das águas no período romano, cuja rede físiográfíca foi certamente aproveitada e desenvolvida pelas ocupações posteriores, mormente no tempo de permanência árabe. É precisamente a investigação arqueológica recente que nos fornece alguns dados importantes sobre a eventual rede de captação, distribuição e de utilização das águas no território de Sellium. A cidade-capital de Sellium é, por assim dizer, o principal polo de uma política e programa de instalação da rede hidráulica no núcleo urbano romano.

\subsection{Area urbana}

Os achados fortuitos e as intervenções arqueológicas nestes últimos 20 anos ( $\left.{ }^{3}\right)$ têm fornecido importantes pistas sobre o aproveitamento das águas do vale do Nabão. Fixemo-nos, em primeiro lugar, nos testemunhos materiais existentes e detectados no espaço urbano. A fundação da cidade obedecia a um programa de urbanização munido de uma rede hidráulica, de edifícios urbanos e de uma malha viària, que traduzisse o estatuto político-administrativo do territorium seliense. Os Romanos souberam aproveitar as características geofisiográficas do vale do Nabão, instalando aí um sistema hidráulico de captação e de alimentação de água à população urbana. Os vestígios arqueológicos fazem supor que o aproveitamento destas águas se faria, fora do perímetro urbano, para fins industriais. Citemos as áreas periféricas de Marmelais/Ferrarias ( $\left.{ }^{4}\right)$.

$\left(^{3}\right)$ Cf. Ponte (S. da) et alli, "Sellium na História Antiga Peninsular", II Congresso Peninsular da História Antiga, Coimbra, 1993, pp. 511-550 (p. 511-515); Cf. PONTE (S. da), "Achegas sobre a estrutura urbana de Sellium (Tomar)", Actas del XXII Congreso Nacional de Arqueologia, Vigo, 1993, pp. 447-459.

$\left({ }^{4}\right)$ CF. Ferreira (R.) e PONTE (S. da), "A villa suburbana de Cardais (Tomar) - Sua historia”, Actas do Seminário - O Espaço Rural na Lusitânia. Tomar e o seu Território, 1989 (=Actas), Tomar, 1992, pp. 55-57; Cf. PONTE (S. da), "A actividade económica de Sellium (Tomar), "Jornadas Interdisciplinares. Poder e Sociedade (1995), Lisboa (no prelo). 
Os vestígios fisiográficos e arqueológicos permitem-nos reconhecer alguns dos recursos hídricos aproveitados pelos Romanos, para abastecimento de água à cidade, para fins domésticos, públicos e para pequenos núcleos industriais. Assim o confirmam os achados arqueológicos. Os recursos naturais da margem esquerda do rio Nabão favoreciam a instalação da rede hidráulica, como sugerem alguns dados geohistóricos: os subafluentes do Nabão [ribeiro Salgado ou ribeiro das Canas, a leste da antiga Cerrada do João do Couto $\left(^{5}\right)$, a norte o ribeiro dos Gafos $\left({ }^{6}\right)$, nas imediações da Praceta de Santo André, a sul o ribeiro Silvares ( ${ }^{7}$ ), nas imediações das Ferrarias, e a poente, o rio], e a detecção de nascentes [uma, a oriente a cerca de 70 metros da ínsula da Alameda, outra, a sul, a

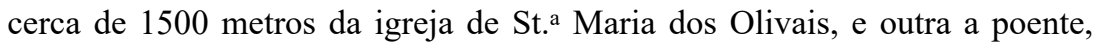
nas imediações da actual Rua do Centro Republicano - antiga Rua das Poças], permitem relacionar estes recursos hídricos com os tanques, poços, fontes e canais romanos de captação, distribuição e evacuação de águas. Os tombos da Baixa Idade Média $\left(^{8}\right)$ referem-se à existência de ribeiros, nascentes e fontes na Cerrada de João do Couto, onde teve assento a cidade-capital de Sellium $\left({ }^{9}\right)$. Estes recursos hídricos foram

$\left(^{5}\right)$ Cf. PONTE (S. da), "Tomar e o seu Território-problemática e perspectivas futuras", Actas , pp. 25-29 (p. 27). O Ribeiro das Canas era também designado por EFFon ou Evon, no tempo romano; na Baixa Idade Média era conhecido por ribeiro dos Gafos, e hoje por ribeiro salgado ou das Canas. As suas águas provinham de zonas elevadas e das águas das chuvas.

(6) Cf. $A M T$ (1542), op. cit. , (nota 2).

( 7 ) Cf. id. ibidem.

$\left.{ }^{8}\right)$ A carta aerofotogramétrica, na Esc. 1:1000 assinala com as manchas A e B, o sítio de destruição de condutas subterrâneas à cota aproximada de 57.30 e 58.40 metros, no sentido N/S e E/W.

$\left.{ }^{9}\right)$ Estudos recentes apontam para a possibilidade do topónimo de Sellium ter sido Seillium, na época augustana. Há já alguma bibliografia sobre esta matéria, facultada por FERnandes (L. da S.), A Presença da Mulher na Epigrafia Romana do Conventus Scallabitanus (dissertação de mestrado em Arqueologia apresentada à FLP, 1996, pp. 5-6), nosso colaborador e epigrafista do período romano: Cf. VASCONCELOS (J. L. de), Inscrição romana de Lorvão, "O Archeologo Português ”, XIX, 1914, pp. 365-366; Cf. Borges (N. C. ), "Lucêncio, bispo de Conimbriga e as origens do Mosteiro de Lorvão", Conimbriga, XXIII, 1984, pp. 143-158; Cf. PEREIRA MENAUT (G.), Corpus de Inscricións Romanas de Galicia, vol. I - Provincia de A Coruña , Santiago , 1991, pp. 199-200, n. ${ }^{\circ}$ 78. O epigrafista FERNANDES apresenta as razões pelas quais prefere referir o topónimo com a grafia Seilium, considerando-a a mais correcta, porque as inscrições funerárias apresentam aquela grafia; esta corresponderia, na opinião deste autor, "ao nome da

Conimbriga, 35 (1996) 189-205 
aproveitados e inseridos nos vários sistemas hidráulicos de Tomar, desde os Romanos à era da hidráulica industrial. Os vestígios materiais romanos são ainda insuficientes para o estabelecimento de uma rede de captação, armazenamento, elevação e distribuição de águas a esta cidade. Procuraremos apenas relacionar os vestígios romanos com as linhas de água reconhecidas e com as referências escritas medievais. É neste panorama paleo-hidrológico e arqueo-histórico, que apresentaremos, como hipótese de trabalho, o sistema hidraúlico da cidade.

\section{a) Fontes e aqueduto}

Ao analisar a rede hidrográfica e a estrutura geológica e litologica de Tomar verifica-se que a maioria dos cursos afluentes do Nabão possui as suas nascentes em terrenos muito permeáveis, constituídos por formações carbonatadas e areníticas do Mesozoico; estas provinham de lençóis aquíferos subterrâneos (galeria de aqueduto, a sul da Praceta de St. ${ }^{\circ}$ André e a leste da ínsula da Alameda) e de ressurgências ou absorção de águas do Nabão, a montante (nascente ou fonte do Choupo, Fonte ou Pego de St. ${ }^{a}$ Iria e nascente ou fonte de Marianaia). Esta área reúne várias nascentes e poços, para além de ribeiros e regatos, que, em épocas de precipitação pluvial, comportavam suficiente água, para a regularização dos lençóis aquíferos. E evidente que desconhecemos a quantidade de água disponível nos cursos de água que atravessavam a região, nem temos tão pouco dados paleogeográficos que referenciem qual a capacidade de escoamento das mesmas; por outro lado, ignoramos os valores de precipitação (absoluta e relativa) e de estiagem em tempos antigos, que condicionavam ou propiciavam o aumento de capacidade dos recursos secundários que abasteciam a cidade. Os níveis friáticos a cotas razoavelmente elevadas concorriam para a acumulação das águas. A abundância de poços propiciava uma melhor regularização dos lençóis aquíferos. Ora, a mina conduzia a água da nascente, através de uma rede

localidade, tal como era pronunciado no século I, sendo a grafia do Itinerário de Antonino uma deturpação do nome, própria da época em que foi redigido (HEp 1, 1989, n. ${ }^{\circ} 112$; Quintana de la Serena, Badajoz)". Esta última informação foi-lhe fornecida por Amílcar Guerra, sugerindo que Seilium seria a pronúncia original, correspondente à grafia Saelium, em latim de boa época, sendo a grafia do Itinerário de Antonino o reflexo de uma época em que a fonética do ditongo - ae - correspondia a !e /. 
de canais, para tanques de captação em pedra e opus signinum. Associada ao polo de captação e condução das águas da nascente, das linhas de água, afluentes ou subafluentes do rio, teria existido uma espécie de larga e funda conduta subterrânea, no sentido N/S, em tijolo e alvenaria (Fig. 1, n. ${ }^{\circ}$ 1), um dos principais colectores da cidade, que se subdividiria em ramos secundários. Para além destas condutas, que ocupariam quase todo o perímetro da cidade, corria, na zona baixa, pelo menos, uma levada ou canal, no sentido $\mathrm{N} / \mathrm{S}$, que de montante para jusante abastecia toda a periferia da margem esquerda (Fig. 1, n. ${ }^{\circ}$ 2), onde se supõe que existiriam fontanários e outras instalações de utilidade pública. Este sistema estava directamente associado ao rio, construindo-se açudes ou diques, rodas hidráulicas, que obrigavam a elevação de água. As rodas hidráulicas existentes na cidade elevavam a água, por meio da força humana ou da própria força motriz. Os relatos medievais são prolíferos quanto à existência deste processo de elevar a água, sendo o seu uso ainda presente no séc. XIX. A galeria detectada em 1986, nas imediações da ínsula da Alameda (Fig. 1, n. 3 e Foto 1), foi nessa mesma altura destruída pelas obras de construção de imóveis, de um dia para o outro. A sua estrutura, bem como outros vestígios de condutas detectadas nas imediações $\left({ }^{10}\right)$, igualmente destruídas, entre 1994/95, pertenceriam à rede de captação e abastecimento de água à cidade. Presume-se, pelos achados detectados, que, no tempo dos Romanos, e devido ao caudal das águas do rio e das nascentes aí existentes, aqueles testemunhos materiais estariam associados à mina de água, abastecendo, assim, a cidade seliense. Esta mina é um túnel estreito ( ${ }^{\mathrm{u}}$ ), de natureza cársica, aberto na camada friática do terreno $\mathrm{e}$ orientado no sentido $\mathrm{E} / \mathrm{W}$. As águas desta mina, à cota aproximada de 58.40 metros, e as da nascente de Marmelais, à cota aproximada de 60.00 metros, abasteciam a cidade, através de uma rede de condutas de pedra e de tijolo, que desaguavam em poços - cisterna e em tanques de captação para armazenamento e transporte de água para as actividades públicas, domésticas e industriais. Foram detectados, no sentido N/S, vestígios de condutas subterrâneas (Fig. 1, n. ${ }^{\circ}$ 4), que canalizavam a água proveniente da nascente de Marmelais, a qual corresponderia ao encanamento das águas para a cidade. Estas

(10) Estes testemunhos foram descobertos por António Ventura, docente na ESTGT.

(n) As dimensões visíveis da mina são aproximadamente de lmx 350x900 mm. 
canalizações, à cota aproximada de 58.30 metros, eram em tijolo, cujas paredes laterais, de opus latericium, eram rematadas em abóbada de arco perfeito; o canal tinha uma largura de $0,60 \mathrm{~mm}$ e de altura cerca de $0,90 \mathrm{~mm}$. Estas dimensões são aproximadas, dada a sua destruição, antes de serem desenhadas à escala e fotografadas. Supomos que estas condutas subterrâneas associadas à mina de água e a vários vestígios arqueológicos achados nas imediações constituiriam a base da rede hidráulica seliense (Fig. 1), tendo como colector ou cloaca máxima, a construção de alvenaria (Fig. 1, n. ${ }^{\circ} 6$ e Foto 3) situada a poente da ínsula da Alameda, à cota de 60.28 metros. Aqui confluíam os esgotos provenientes das casas e das oficinas artesanais, como atestam as duas condutas, com orientações diferentes: uma, à cota de 59.98 metros, corre, no sentido EAV, sob o pavimento da rua, contígua à ínsula da Alameda, recolhendo a água utilizada pelas casas de vizinhos (Fig. 1, n. ${ }^{\circ}$ 7); outra, à cota de 60.30 metros, e no sentido $\mathrm{N} / \mathrm{S}$, recolheria certamente as águas usadas pelas oficinas domésticas instaladas para noroeste da área comercial e residencial (Foto 2). A abertura destes canais não ultrapassava os 0,30 metros (Fig. 1 , n. ${ }^{\circ} 8$ e Foto 4). As águas usadas, uma vez na cloaca máxima, seguiam em direcção ao rio Nabão. A adutora das águas da mina e da nascente de Marmelais teria necessariamente ramificações, das quais apenas detectámos uma, em direcção a um tanque ou castellum de armazenamento e distribuição de água potável (Fig. 1, n. ${ }^{\circ}$ 9), pelo menos, para a ínsula da Alameda. Esta estrutura, de planta rectangular, apresenta interiormente 3 bacias, uma das quais do lado sul, quase inexistente; a peça intermédia tem cerca de 2.40 metros de comprimento por 1.70 metros de largura, enquanto que as dimensões da peça a norte são aproximadamente de 2.45 metros de comprimento por 2.10 metros de largura. Esta construção de alvenaria e de tijolo tem cerca de 7.00 metros de comprimento, sendo ainda visíveis, do lado sul, vestígios de conduta, em direcção à bacia, do mesmo lado; foram igualmente detectados vestígios de conduta de alimentação de água à ínsula, do lado poente, por uma estrutura rectangular interrompida, na extrema do tanque norte, com cerca de 1.10 metros por 0,60 metros de largura, cujas paredes exteriores tinham de largura cerca de 0.30 metros. A base deste reservatório encontrava-se à cota de 59.12 metros, conservando vestígios de dois septos laterais, definindo provavelmente uma das portas, que possibilitaria o abastecimento de água à ínsula; a cerca de 20 metros para poente, foram descobertas várias ramificações de canais de abastecimento a 
diversas zonas da ínsula e a outras áreas, mais próximas da actual travessa da Cascalheira (Fig. 1, n. ${ }^{\circ}$ 5). Os materiais de construção recolhidos nas imediações do tanque, de planta rectangular, fazem-nos supor que o reservatório era constituído por uma abóbada de volta inteira. Os arranques das partes laterais eram constituídos por pequenos blocos calcários argamassados, assentes num lastro de pedra e seixo unidos. O revestimento interior era de opus signinum e recoberto por uma camada fina de argamassa, conforme os resíduos materiais detectados. E uma construção augustana, de acordo com os materiais encontrados (12), destacando-se algumas peças cerâmicas e metálicas de datação segura.

Há referências modernas (13) sobre a existência de uma abóbada, que sustentaria um vão, para além de muita pedra de alvenaria, e que, no nosso entender, não seria mais do que uma peça do aqueduto principal da cidade. Estas ruínas situar-se-iam para norte do cemitério velho, nas imediações da azinhaga do ribeiro Salgado ou das Canas, entre a actual Rua Diogo de Arruda e a Rua D. Maria II.

Estas condutas de pedra calcária estavam aproximadamente à cota de 59.32 metros, tendo de largura cerca de 0.40 a 0.60 metros. A proliferação de poços e a existência de água subterrànea em abundância em toda a margem esquerda do rio facilitaram a instalação de urna rede de captação e de distribuição de água potável à população seliense. E de referir ainda a área correspondente entre a antiga Rua Larga (Rua Marquês de Tomar) e a Rua das Poças (Rua do Centro Republicano), que forneceu, nos tempos medievais e modernos, diversos testemunhos arqueológicos, tais como canalizações, alicerces de habitações, etc. Por outro lado, as áreas mais próximas do rio, a uma cota aproximada de 51.80 e 53.30 metros, eram certamente abastecidas pelas águas provenientes do Agroal, da ribeira de S. Gregorio (14), da nascente do Choupo ( $\left.{ }^{15}\right)$, de Marmelais, e da captação das águas pluviais. Existem ainda vestígios de uma "levada antiga" que estaria em ligação com canais secundários destinados à rega, à indústria e provavelmente para

(12) Duas moedas augustanas, paredes finas, sigillata sudgálica, etc.

(13) CF. Sousa (J. M.), op. cit. (nota 2), pp. 231-232. O autor refere que esta pedra foi aproveitada para a construção de mausoléus.

(14) A ribeira de S. Gregório foi entulhada, entre 1919/1920. Esta água era bastante calcária provocando perturbações digestivas.

(15) CF. Mela (R.), "Ruas de Tomar e a sua Toponímia", Boi. Cult., 2 , Out. 1981, pp. 75-86 (p. 86). O autor refere-se à nascente que foi vedada nos finais do séc. XIX. 
abastecimento de complexos habitacionais suburbanos. A villa de Cardais era abastecida pela nascente de Marmelais (ribeiro de Cardais), e pelas águas da "levada" supondo-se que as águas sujas iriam directamente para uma outra cloaca situada na propriedade dos herdeiros de Albino de Lima Simões $\left({ }^{16}\right)$, detectada recentemente pelas profundas transformações efectuadas no local onde foi construído um edifício para a $3^{\text {a }}$ idade $\left({ }^{17}\right)$. E plausível que a abundância de águas ao longo das margens do rio fosse regularizada e canalizada para diversos fins domésticos e industriais. O represamento das águas através de açudes e de rodas hidráulicas poderá, no nosso entender, remontar ao período romano. É evidente que não possuímos provas irrefutáveis destes aparelhos elevatórios, senão indícios residuais, a montante do rio Nabão, e que nos parecem, pela alvenaria e argamassa usadas, da época romana. Há, assim, vários testemunhos arqueohistóricos $\left({ }^{18}\right)$, que nos apontam para a existência de sistemas de construção hidráulica largamente usadas na época clássica e medieval. Referimo-nos aos açudes e às rodas hidráulicas que alimentavam os sistemas de rega e de fabricação de farinha e de azeite. Muitos desapareceram, outros deixaram marcas mais ou menos evidentes, e outros conservam-se em ruínas (Fig. 5), ou caso mais raro resistem intactos aos agentes naturais e à acção do homem. A "levada" antiga que abastecia de água a villa de Cardais, segundo a tradição oral, fazia mover um engenho (moinho, azenha e roda hidráulica) destinado à moagem do grão em farinha. Esta villa suburbana ficava a jusante do açude e ponte das Ferrarias, designada por "dorso de burro" $\left.{ }^{19}\right)$. Esta ponte resolvia os problemas da lezíria, quase sempre alagada pelas águas do rio, que

(16) Cf. Guimarães (V.), op. cit. (nota 2), pp. 92-93. O autor refere "que a um cano, "se ainda existir ", cuja enorme boca gradeada se vê perto duma grande massa de calcareo rijo que na margem esquerda do Nabão aflora, um pouco abaixo do limite sul que assinalamos a Sellium, na propriedade, hoje dos herdeiros.

$\left.{ }^{(17}\right)$ O imóvel para a $3^{\text {a }}$ idade construído nas imediações e defronte da igreja de St. ${ }^{a}$ Maria do Olival forneceu, aquando da abertura de caboucos, alguns tanques/ /cisternas, canalizações e troços do caminho antigo de Marmelais, conservando-se alguns desses testemunhos na nova integração construtiva.

(18) Cf. Ferreira (F.), op. cit., (nota 2), pp. 9-13; CF. Guimarães (V.), op. cit. (nota 2), pp. 13-14.

$\left({ }^{19}\right)$ CF. Guimarães (V.), op. cit. (nota 2), pp. 13-14. Esta ponte, totalmente destruída, dava ainda "passagem no séc. XIV, segundo Femão Lopes, na Crónica de EL-Rei D. João I; Cf. SAlema (V. de S.), "As Ferrarias do concelho de Tomar", Boi. Cult. ,7, 1984, pp. 113-119. 
no séc. XIII era conhecida por Nava de Juncoso $\left({ }^{20}\right)$. Aqui foram detectadas cisternas, tanques, poços e várias canalizações, provenientes de estruturas de captação e de evacuação das águas, como a identificação de urna cloaca ${ }^{(21)}$.

Há cerca de 60 anos vislumbravam-se ainda na margem esquerda do Nabão, um pouco acima da ponte das Ferrarias, uma vala ou canalização em direcção à villa de Cardais $\left({ }^{22}\right)$, o que supomos ser o encanamento das águas do rio naquela área. Hoje está assoreado, dado o alteamento do leito do rio. Por outro lado, esta conduta seria a mesma que é citada por Pedro Álvares Seco (séc. XVI), nas suas Crónicas : uma vala coberta que trazia água ao Convento das Clarissas (antigo convento de St. ${ }^{a}$ Iria), depois de mais uma captação junto ao açude dos Frades (D. Henrique mandou aprofundar esta vala ou canal, designada por canal do Mouchão, para saneamento dos terrenos da Várzea Pequena), atravessava a Rua Marquês de Tomar, os terrenos do Estádio Municipal, e desaguaria junto à Horta d'El-Rei (Estádio Municipal/azinhaga das Hortas). O Tombo da Igreja de Santa Maria do Olival Paroquial e Matriz desta Villa de Tomar e seus Termos (ANTT, fl. 123 v.) refere-se a uma fonte (Pego) sobre o rio, defronte do convento das monjas, com água limpa e "que de longe vinha por debaixo da terra por canos de pedra..." (antigo palácio de Castinaldo, governador de Selio, em 653). A existência de moinhos de água (mola aquaria) ou de moinhos de mão (trusabilis), de poços domésticos (,girgilus), de rodas hidráulicas (rota aquaria) com os seus alcatruzes de madeira (modioli) ou de barro (rotarum cadi) ficou gravada na memória das gentes, que habitaram a dita "Nabância", ou seja, foram senhores, homens livres, convidados e escravos desta villa de Cardais. As águas de Marmelais, que ficam a pouco mais de $1 \mathrm{Km}$ da cidade de Tomar, provêm de rochas siliciosas, sendo insípidas, inodoras e límpidas, com qualidades terapêuticas para doenças gástricas e intestinais. As características físico-químicas destas águas e as referências arqueo-históricas permitem-nos calcular aproximadamente quais foram as fontes de abastecimento e de aproveitamento aquífero, no tempo dos Romanos.

$\left({ }^{20}\right)$ Cf. Ponte (S. da), op. cit. (nota 3), p. 448.

(21) Cf. Guimarães (V.), op. cit. (nota 2), p. 82-84.

Conimbriga, 35 (1996) 189-205 


\subsection{Area rural}

a) Rodas e açudes

O represamento das águas do rio tem servido, desde o período clássico à actualidade, para a regularização do seu caudal, mas também para o aproveitamento das populações que se fixaram no território seliense.

As rodas hidráulicas alimentavam os sistemas de rega e de fabricação de farinha e de azeite. As referências históricas são maioritariamente da época medieval e moderna $\left({ }^{23}\right)$, remontando o seu uso à presença árabe, para depois com a Ordem do Templo e dos Cavaleiros de Cristo, terem uma larga aplicação nas terras férteis do Nabão. Não detectámos ainda estruturas romanas que possam assegurar o uso da roda hidráulica de aro compartimentado. Conhecemos, no entanto, réplicas de modelos romanos $\left({ }^{24}\right)$ e vestígios residuais de suportes em alvenaria, para a fixação da roda hidráulica de aro compartimentado. Estes testemunhos materiais encontram-se em férteis terrenos agrícolas, que teriam sido villae, pagi ou casais. Referimo-nos ao Casal dos Frades (Freg. de S. João Baptista), Casal das Vargas ou Várzeas (Freg. da Pedreira) e Casal de Chocapalhas (Freg. da Junceira), que têm fornecido diverso material romano $\left({ }^{25}\right)$. Estas rodas eram de construção bastante sólida e semelhante à dos moinhos e azenhas de roda vertical, aparecendo umas e outras associadas; a água que corria pelo mesmo canal ou gola movia os dois aparelhos. Este modelo de roda é vulgar nesta região, e, segundo a tradição desde a época árabe. Tomar ostenta como ex-libris a roda do Mouchão. Entendemos que este modelo foi divulgado pelos Árabes, existindo este sistema de elevação da água já na época romana. Os suportes de alvenaria ainda existentes em várias zonas do rio e nas imediações de algumas villae reforçam esta nossa

(22) Cf. Sousa (J. M.), op. cit. (nota 2), p. 234.

(23) Cf. Ferreira (F.), op. cit. (nota 2), pp. 9-13; Cf. Rosa (A.), op. cit. (nota 2), 1982, pp. 131-132; Cf. Dias (Jorge) e GalHano (Fernando), Aparelhos de elevar a água de rega, Lisboa, 1986; Cf. Oliveira (E. V.), Galhano (F.) e Pereira (B.), "Sistemas de moagem (Tecnologia Tradicional-Etnologia)", Etnologia, 2, Lisboa, 1983.

${ }^{(24)}$ Cf. Ferreira (F.), op. cit. (nota 2), pp. 59-71; Cf. Ponte (S. da), "O rio, as rodas e os açudes", Boi. Cult., (17), Out. 1992, pp. 43-48.

(25) Cf. Dias (J.) e Galhano (F.), op. cit. (nota 23), p. 49; Cf. Ferreira (F.), op. cit. (nota 2), p. 71. 
hipótese de trabalho (Foto 5). O fabrico destas rodas exigia a mão de carpinteiros especializados (26), os quais utilizavam para a sua construção o pinheiro (manso e bravo) e o carvalho; as rodas em ferro vulgarizam-se a partir do séc. XVIII. Estes engenhos eram vulgares na Estremadura e no Ribatejo. Caracterizam-se por terem um elemento central ou eixo (peça oitavada) constituído por dois discos, donde irradiam os raios; estes são reforçados por uma espécie de gradeamento losangonal, em pinho. Esta construção é envolvida por uma "cinta", constituída por tiras estreitas de madeira, ou "penas", fixas à roda, que serviam de degrau ou patamar para o homem que movia o engenho, ou, depois, para a fixação dos alcatruzes. O suporte da roda ou "burra" era de pinho, passando posteriormente a ser de alvenaria; o restante, à excepção do eixo, que era feito de carvalho, era de pinho bravo. Os alcatruzes presos aos arcos da roda eram de barro ou de folha. Estes engenhos, associados, muitas das vezes, a azenhas de roda vertical, apresentavam sistemas ou dispositivos especiais, que visavam responder às condições criadas pela diferença de nível das águas do Nabão e das ribeiras suas tributárias, registadas no verão e no inverno. Por outro lado, a construção e a orientação destes engenhos, perto das margens do rio, que apresentavam um grande caudal no período das chuvas, obedeciam a dispositivos arquitectónicos de segurança dos próprios edifícios, evitando, assim, a sua destruição pela violência das águas. Estas construções tinham habitualmente a fachada orientada para montante, em forma de quebramares de pedra, ora aguçados, em esquina, ora arredondados ${ }^{(27)}$. Os resíduos arqueológicos, ainda perceptíveis, de alguns destes engenhos hidráulicos permitem-nos comparar com outras instalações hidráulicas romanas $\left({ }^{28}\right)$, que apresentam características idênticas, na estrutura, materiais e sistema de represamento e de elevação de água.

Citemos as rodas accionadas pela energia humana, nas minas de Tarsis, em Huelva, na Andaluzia, e de S. Domingos, em Mértola. Vitrúvio, no seu livro De architectura descreve o sistema de rodas de

(26) CF. Dias (J.) e GalHano (F.), op. cit. (nota 23), p. 110.

(27) CF. Quíntela (A. C.), Mascarenhas (J. M.) e Cardoso (J. L.), "Instalação romana de captação, elevação e armazenamento de água em Troia (Grândola, Portugal)”, Conimbriga, 32-33 (1993-94), pp. 157-169 (p. 165).

${ }^{28}$ CF. Ponte (S. da), “Achegas para a Carta Arqueológica de Tomar”, Portugália , 1996 (no prelo).

Conimbriga, 35 (1996) 189-205 
água verticais, de palas e alcatruzes, umas accionadas pelo homem e outras por uma corrente. A estrutura em alvenaria de alguns suportes para rodas hidráulicas existentes a montante da cidade de Tomar é paramentada interiormente por pequenos blocos calcários e terra argilosa compactada, sendo exteriormente revestida por uma argamassa de cal, de diferentes qualidades; a argamassa exterior e superficial é fina e esbranquiçada (Foto 5). Estas estruturas associam-se a condutas, caleiras, azenhas e açudes largamente usados pelas populações passadas. Referimo-nos a testemunhos arqueológicos existentes nas duas margens do rio, como sejam vestígios de engenhos hidráulicos no lugar de Vale Carvalho, de Coutadas, do Sobreirinho, das Lapas, do Canteirão, Porto da Figueira, etc (Fregs. de Além da Ribeira e da Pedreira). Estas pré-existências situam-se entre o actual açude de Pedra (Freg. de S. João Baptista) e a actual Fábrica do Prado (Freg. da Pedreira).

A existência de unidades agrícolas romanas é-nos atestada pelos achados materiais recolhidos por nós, pela análise do cadastro antigo e pela interpretação da fotografia aérea, para o territorium de Sellium. O açude, em alvenaria, no lugar das Lapas (Freg. Além da Ribeira), serviria também de passadiço, como nos asseveram as estruturas ainda conservadas (Foto 6). O elevado caudal das águas neste lugar durante o inverno e a fertilidade das terras determinaram a instalação de complexos hidráulicos existentes nas duas margens: rodas, azenhas, caleiras e açudes de estacaria e de alvenaria.

A recolha sistemática de testemunhos materiais nestes terrenos e o estudo destes engenhos poderão determinar o tempo de construção e consequente uso da força motriz produzida por todos estes engenhos hidráulicos. Os açudes existentes no Nabão são de dois tipos fundamentais: os açudes de estacaria e os de construção maciça, em alvenaria; os primeiros eram barreiras provisórias de madeira de pinho, erva e areia, instalações tendo em vista a laboração estival de alguns engenhos hidráulicos $\left({ }^{29}\right)$; os outros eram constituídos por pedra calcária e argamassa de cal. A sua construção era duradoira tendo por objectivo regularizar o caudal do rio, com aproveitamento para a agricultura e para actividades industriais ligadas à força motriz. $\mathrm{O}$ açude das Lapas, em alvenaria, consistia numa estrutura maciça, constituída por um muro de blocos calcários argamassados, cuja parede a montante apresenta um traçado arredondado, enquanto que a face a juzante é rectilínea. Esta

(29) Cf. Ferreira (F.), op. cit. (nota 2), pp. 49-50.

Conimbriga, 35 (1996) 189-205 
estrutura estaria relacionada com a rega, como também com o aprovisionamento de água para os engenhos hidráulicos, e para abastecimento da villa romana das Lapas (Freg. Além da Ribeira).

\section{b) Barragem}

As características estruturais do muro existente no lugar de Chocapalhas (Foto 7 e Mapa 1, n. ${ }^{\circ}$ 1) apontam para a presença de uma barragem antiga, muito provavelmente romana ou tardo-romana. Os vestígios materiais recolhidos nas imediações e o tipo de estrutura e construção fazem-nos admitir que esta barreira física possa ser de origem romana. Esta construção, em alvenaria, com uma ponte romana (Mapa 1, n. ${ }^{\circ}$ 2) a jusante destinava-se essencialmente a rega $\mathrm{e}$ ao abastecimento da villa romana.

O complexo hidráulico de Chocapalhas era constituído por várias azenhas e rodas hidráulicas de aro interrompido, existindo apenas hoje diversos resíduos daquelas construções. Esta barragem situa-se na ribeira da Lousã, freguesia da Junceira, tendo como coordenadas quilométricas UTM, 4384, 06/555, 06, referente à folha 310. Apresenta um muro de alvenaria - opus incertum — de secção rectangular, com aterro a montante e provida de uma descarga de fundo com cerca de $600 \mathrm{~mm}$ de altura por $400 \mathrm{~mm}$ de largura. O coroamento da barragem é constituído por lajes, em alvenaria, sendo o núcleo constituído por blocos calcários argamassados. As paredes a montante e a jusante são rectilíneas. Tem cerca de 2.00 metros de largura por 3.30 metros de altura e 50 metros de comprimento. A área da bacia hidrográfica teria cerca de $30 \mathrm{~m}^{2}$. A ponte romana fica a cerca de 400 metros a jusante da barragem e de um lagar de azeite que existia nas imediações daquela. A cerca de $1 \mathrm{Km}$ da barragem foram achados vestígios de um provável núcleo urbano secundário, entre a Paixinha e o lugar de Chocapalhas, à cota de 66 metros (Mapa 1, n. ${ }^{\circ}$ ).

\section{Conclusão}

O território seliense conserva ainda bastantes vestígios de estruturas hidráulicas, ainda por estudar e divulgar, estando algumas delas associadas a núcleos urbanos romanos; outras, porém a casais medievais e modernos. Umas e outras impõem um estudo aprofundado e sistemático, para que se conheçam os vários hidrossistemas antigos usados pelas populações selienses. 
(Página deixada propositadamente em branco) 
(Página deixada propositadamente em branco) 


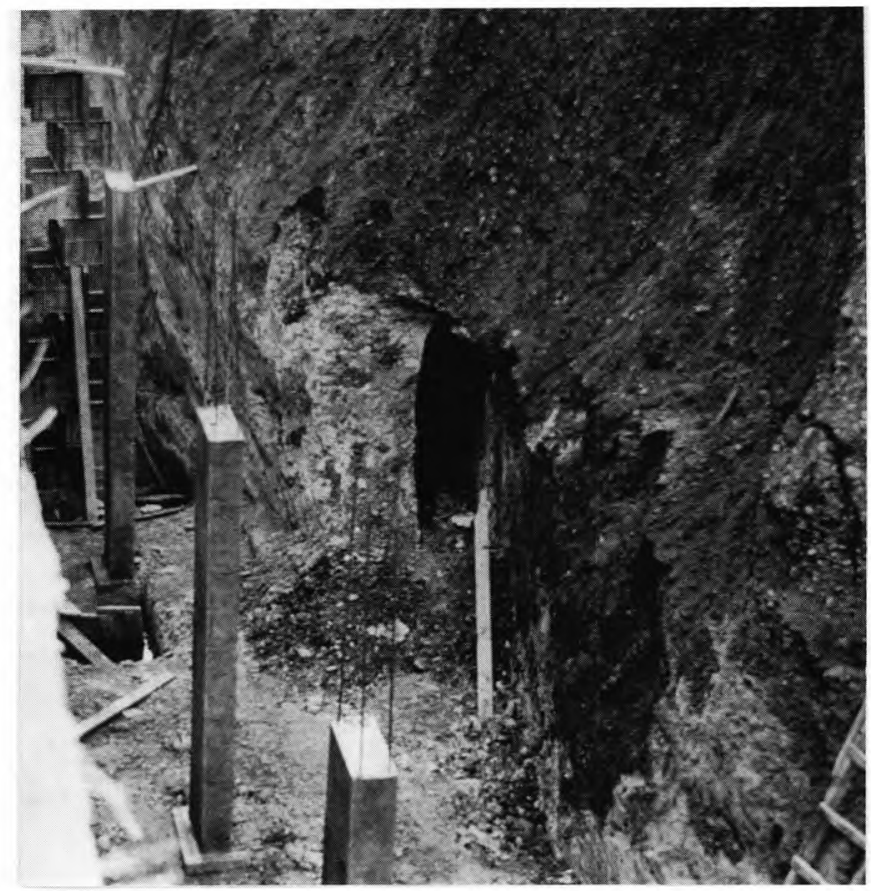

Fото 1 - Pormenor da mina de água.

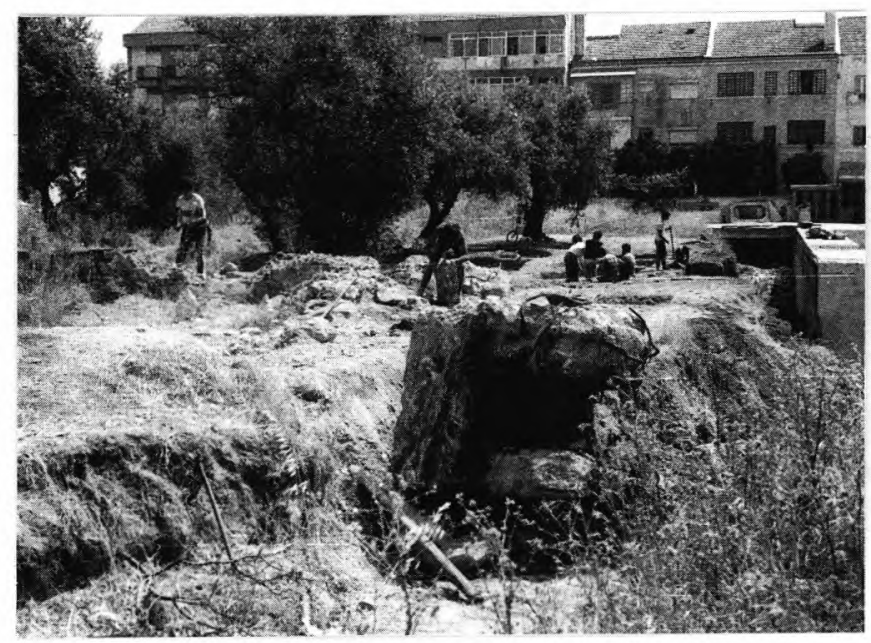

Fото 2 - Aqueduto subterrâneo romano. 


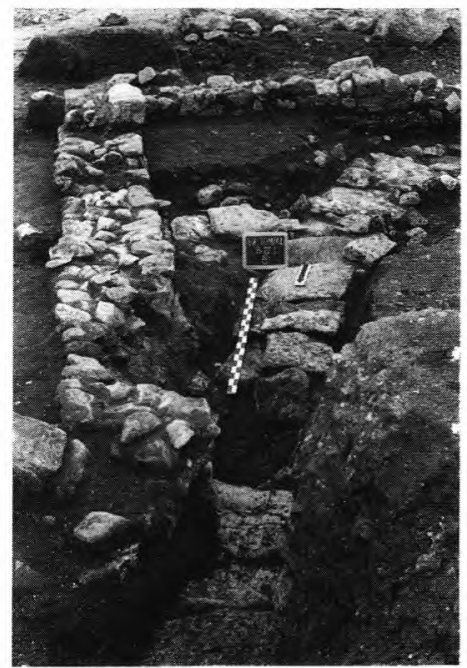

Foto 3 - Vestígios de colector a poente da ínsula da Alameda.

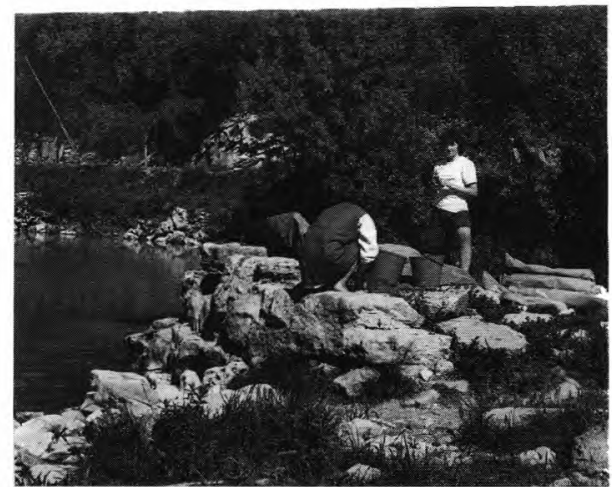

Fото 6 - Pormenor de açude, em alvenaria, no lugar das Lapas.

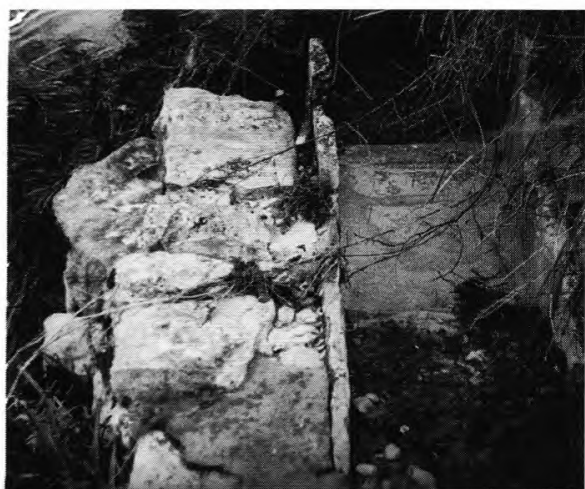

Foто 5 - Vestígios de suporte em alvenaria para roda hidráulica.

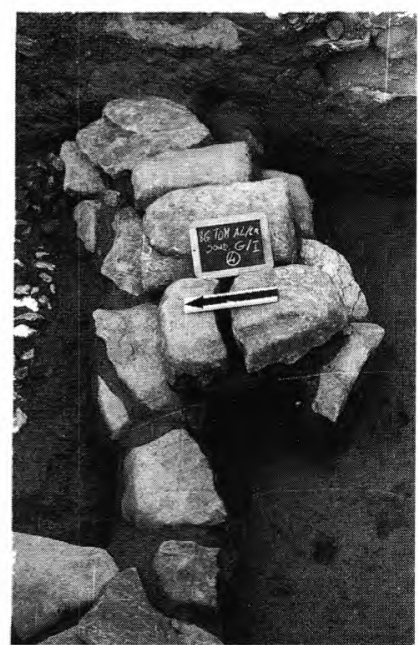

Fото 4 - Vestígios de conduta subterrânea. 


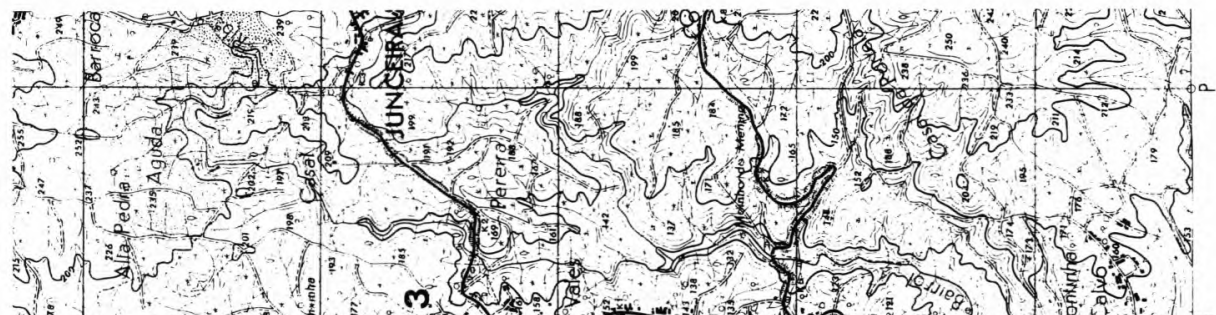

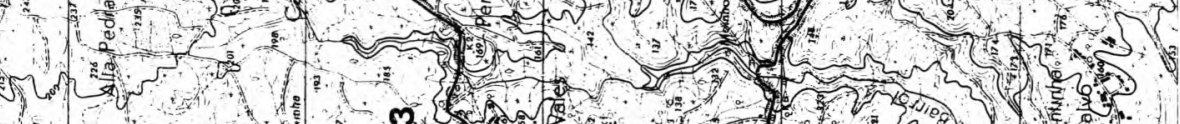
D.

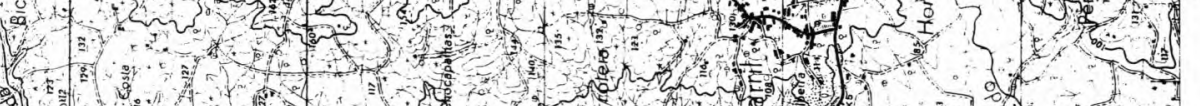
(1)

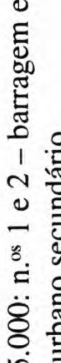
(160. (1)

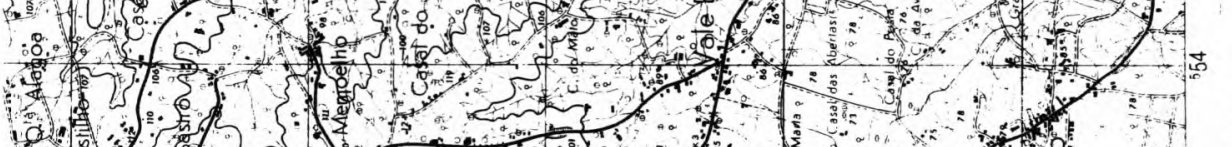

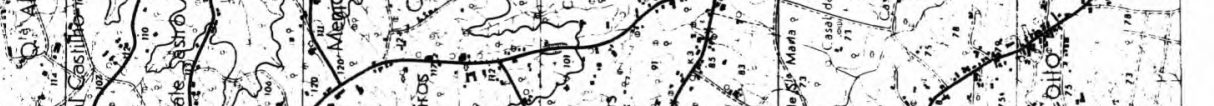
34 .

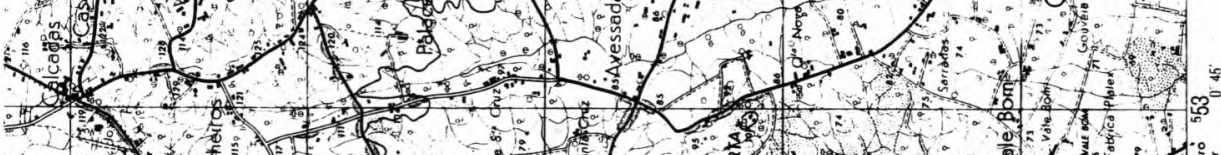
क. (1)

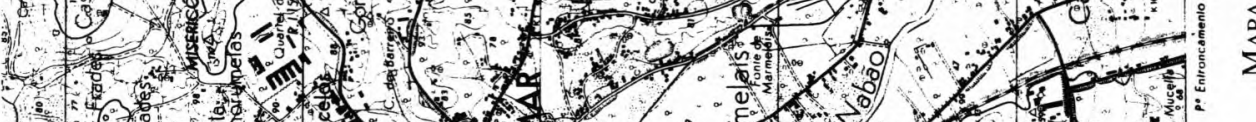
1) 


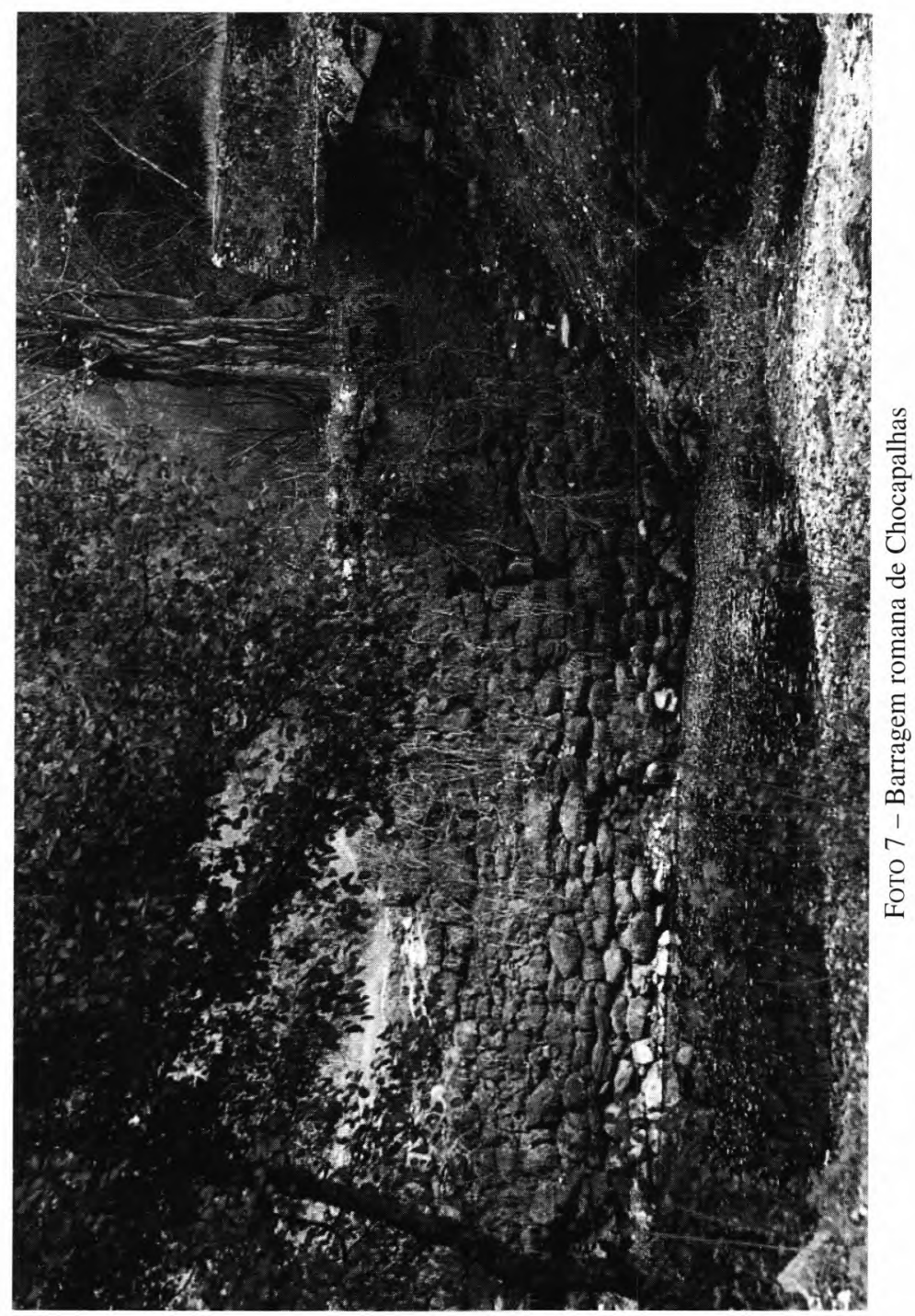

